\title{
Minimum Well Separation for small groundwater heat pump (GWHP) systems in Korea: preliminary analysis based on regional aquifer properties
}

\section{Byeong-Hak Park}

Seung-Wook Ha

\author{
Kang-Kun Lee*
}

\begin{abstract}
Shallow geothermal energy has been estimated to have an excellent applicability in Korea, and its applications for space heating and cooling have steadily increased in recent years. Such application as ground source heat pump (GSHP) system can be classified into closed-and open-loop.

In recent years, studies have been conducted to minimize the environmental impacts resulting from pumping/injection and to enhance the efficiency of groundwater heat pump (GWHP) system that is the open-loop system. These studies suggest that the characteristics of the aquifer have a significant role in designing efficient GWHP systems. This study considers various hydrogeological properties of Korea. An open-source numerical code called TRS was used for preliminary and sensitivity analyses of GWHP systems. In the analyses, arrival time when thermal plume arrives at pumping well and temperature change at pumping well were observed with different pumping/injection rates, hydraulic gradient, and well separation. Thus, we derived adequate well arrangement for efficient GWHP operation.
\end{abstract}

\section{INTRODUCTION}

Among available new and renewable energy sources, shallow geothermal energy that takes advantage of stable underground temperatures has been estimated to have excellent applicability in Korea (Mok et al., 2010). Since the "Promotional Law of New and Renewable Energy Development, Use and Dissemination" was enacted in 2004, the use of ground source heat pump (GSHP) systems in Korea has steadily increased in recent years because of their benefits and the governmental support (Lee, 2009; KEMCO, 2011; Kwon et al., 2012). Such application as GSHP system can be classified into closed- and open-loop systems.

An open-loop system extracts groundwater from one well, exchanges heat energy with the water, and injects the water into another well. In recent years, studies have been conducted to minimize the environmental impacts resulting from pumping/injection and to enhance the efficiency of groundwater heat pump (GWHP) systems (Lo Russo et al., 2011; Zhou et al., 2013). The applicability of groundwater for cooling large-scale facilities has also been estimated (Al-Zyoud et al., 2014). These studies suggest that the aquifer characteristics play an important role in designing the open-loop systems.

However, characterization of the aquifer, which is required to design the efficient system, is very expensive in terms of time and cost, and is not reasonable for small applications. In this context, an open-source numerical code called TRS (Casasso and Sethi, 2015) was selected for preliminary and sensitivity analyses of small-scale GWHP systems because it can deal with flow and heat transport in a well doublet and does not requires much input data. In the analyses,

\footnotetext{
School of Earth and Environmental Sciences, Seoul National University, Seoul 151-747, Rep. of Korea

*Corresponding author. Tel.: +82-2-880-8161

E-mail addresses: pbh3000@snu.ac.kr (B. Park), hasabana@snu.ac.kr (S. Ha), kklee@snu.ac.kr (K. Lee)
} 
arrival time when thermal plume arrives at pumping well and temperature change at pumping well were observed with different pumping/injection rates, hydraulic gradient, and well separation. Thus, we derived adequate well arrangement for efficient GWHP operation.

\section{METHODOLOGY}

The numerical model of TRS is based on a finite-difference approximation of the potential flow theory and deals with thermal recycling phenomenon between injection and production wells with groundwater flow (Casasso and Sethi, 2015). In this study, the model was used to estimate the well arrangement for small GWHP systems which can avoid thermal recycling between wells. In the model, injection well was assumed to be downstream. To consider hydrogeological properties of South Korea, the data obtained from the national groundwater monitoring stations (NGMSs) were analyzed. Figure 1 shows the location of 126 NGMSs considered in this study. The monitoring wells were installed at alluvial layers, which consist of clay, sand, gravel, and weathered rock. Groundwater levels are located at average $4.97 \mathrm{~m}$ below ground surface. Hydraulic conductivities of the alluvial aquifer ranged from $1.12 \times 10^{-5}$ to $2.34 \times 10^{-1} \mathrm{~cm} / \mathrm{s}$ with geometric mean of $9.56 \times 10^{-4} \mathrm{~cm} / \mathrm{s}$ (Figure 2). The range corresponds to the values of sand or gravel (Domenico and Schwartz, 1990) and volumetric heat capacity of such media varies between 2.2 and 2.8 $\mathrm{MJ} / \mathrm{m}^{3} \mathrm{~K}$ (Stauffer et al., 2013). System size for small application was determined to be less than $23.4 \mathrm{~kW}$, based on pumping/injection rates and the statistics of geothermal application (KEA, 2015). Injection temperature was assumed to be $5^{\circ} \mathrm{C}$ higher than temperature of pumped water, and thus the system operated in the cooling mode. Since the numerical model can simulate only a continuous operation, injection temperature of $5^{\circ} \mathrm{C}$ higher or lower make no difference in the analysis results. Pumping/injection rates were set to satisfy the system size. The simulation was performed for ten years, and arrival time when thermal plume arrives at pumping well and temperature change at pumping well were observed with different well flow rates, well distances, hydraulic conductivities, and hydraulic gradients. The input parameters used in the analysis are listed in Table 1.

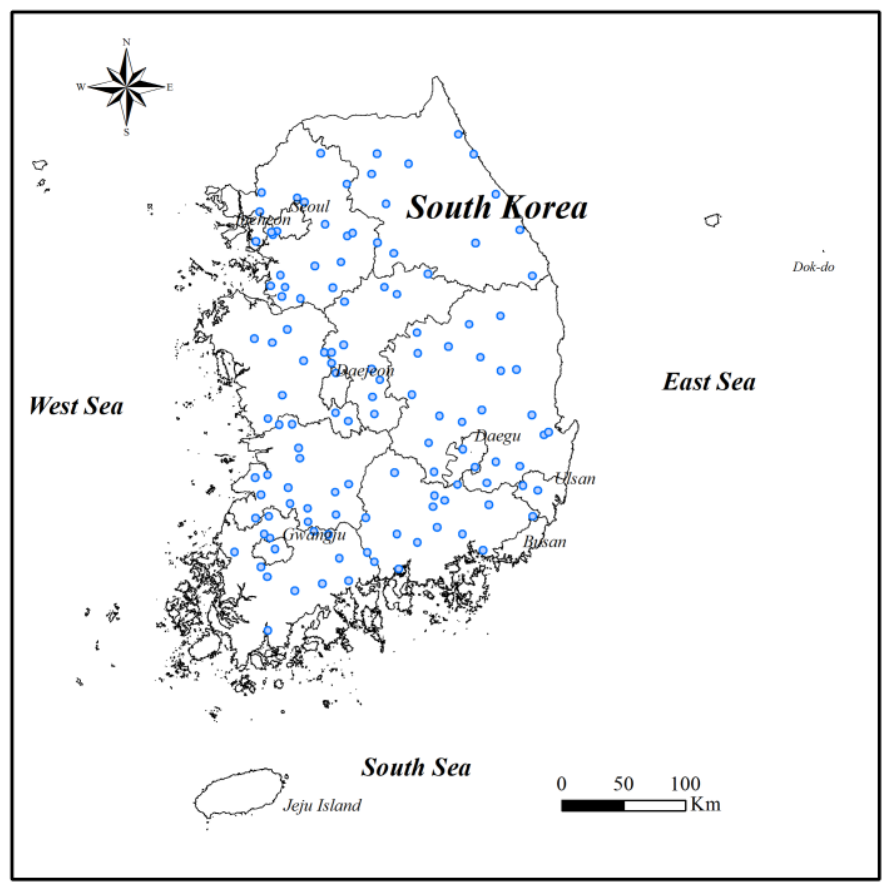

Figure 1 Location of the national groundwater monitoring stations considered in this study. 


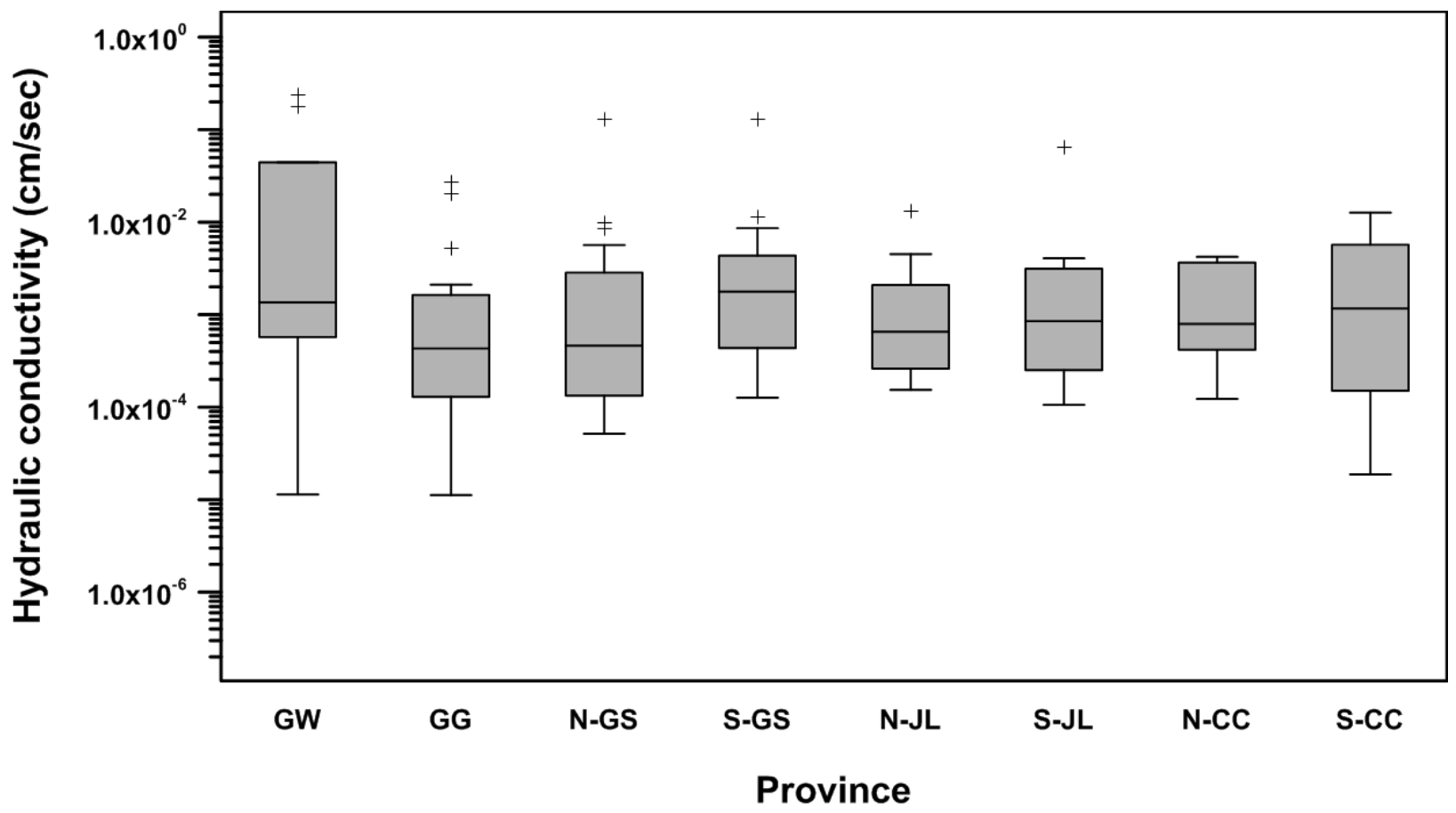

Figure 2 Range of hydraulic conductivities of the alluvial aquifers by province.

Table 1. Model input parameters

\begin{tabular}{lccc}
\hline \multicolumn{1}{c}{ Parameter } & Symbol & Unit & Value \\
\hline \hline Well flow rate & $\mathrm{Q}$ & $\mathrm{m}^{3} / \mathrm{d}$ & 20 to 100 \\
Temperature difference & $\Delta \mathrm{T}$ & $\mathrm{K}$ & 5 \\
Well radius & $\mathrm{r}$ & $\mathrm{m}$ & 0.25 \\
Hydraulic conductivity & $\mathrm{K}$ & - & $10^{-5}$ to $10^{-3}$ \\
Effective porosity & $\mathrm{n}$ & - & 0.2 \\
Hydraulic gradient & $\mathrm{i}$ & $\mathrm{MJ} / \mathrm{m}^{3} \mathrm{~K}$ & 0.001 to 0.01 \\
Thermal capacity of soil & $\varrho^{\mathrm{s}} \mathrm{C}^{\mathrm{s}}$ & $\mathrm{MJ} / \mathrm{m}^{3} \mathrm{~K}$ & 2.5 \\
Thermal capacity of water & $\varrho^{\mathrm{w}} \mathrm{C}^{\mathrm{w}}$ & $\mathrm{m}$ & 4.2 \\
Aquifer thickness & $\mathrm{b}$ & 15 & 15 \\
\hline
\end{tabular}

\section{Results}

Analysis results are shown in Figures 3-5. Minimum well separation is defined as the distance between pumping and injection wells in which thermal recycling does not occur even with a continuous operation during ten years. Under high flow condition $(i=0.01)$, the minimum well separation to avoid thermal interferences varied from 2 to $50 \mathrm{~m}$ when hydraulic conductivity is larger than $10^{-4} \mathrm{~m} / \mathrm{s}$. As flow velocity decreases, the required distance increases and is in the range from 10 to $50 \mathrm{~m}$ when hydraulic conductivity is larger than $4 \times 10^{-4} \mathrm{~m} / \mathrm{s}$ (Figure 5). Considering the low hydraulic conductivity value reported for some monitoring wells, the necessary distance become too large to apply small GWHP systems when groundwater flow is very low (Figure 5). Therefore, groundwater flow condition play a 
significant role in small-scale facilities, and such applications can be limited by available space especially in case of very low flow velocity.

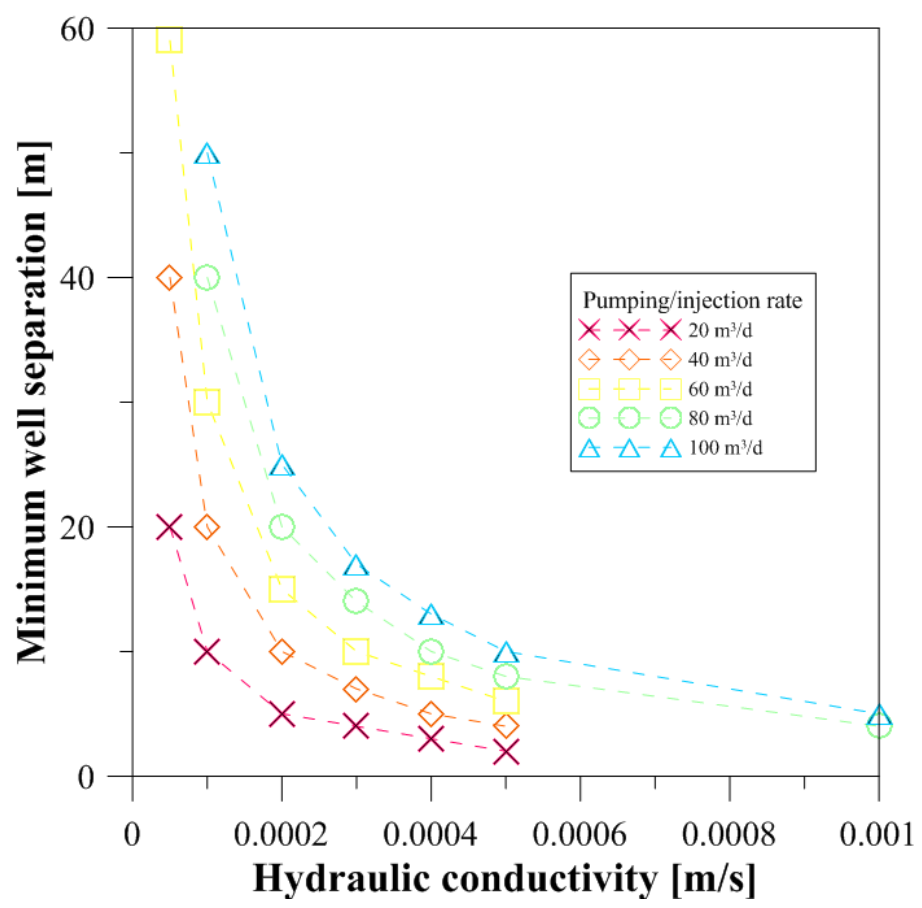

Figure 3 Minimum well separation according to various pumping/injection rates and hydraulic conductivity under high flow condition (hydraulic gradient $\mathrm{i}=0.01$ ). 


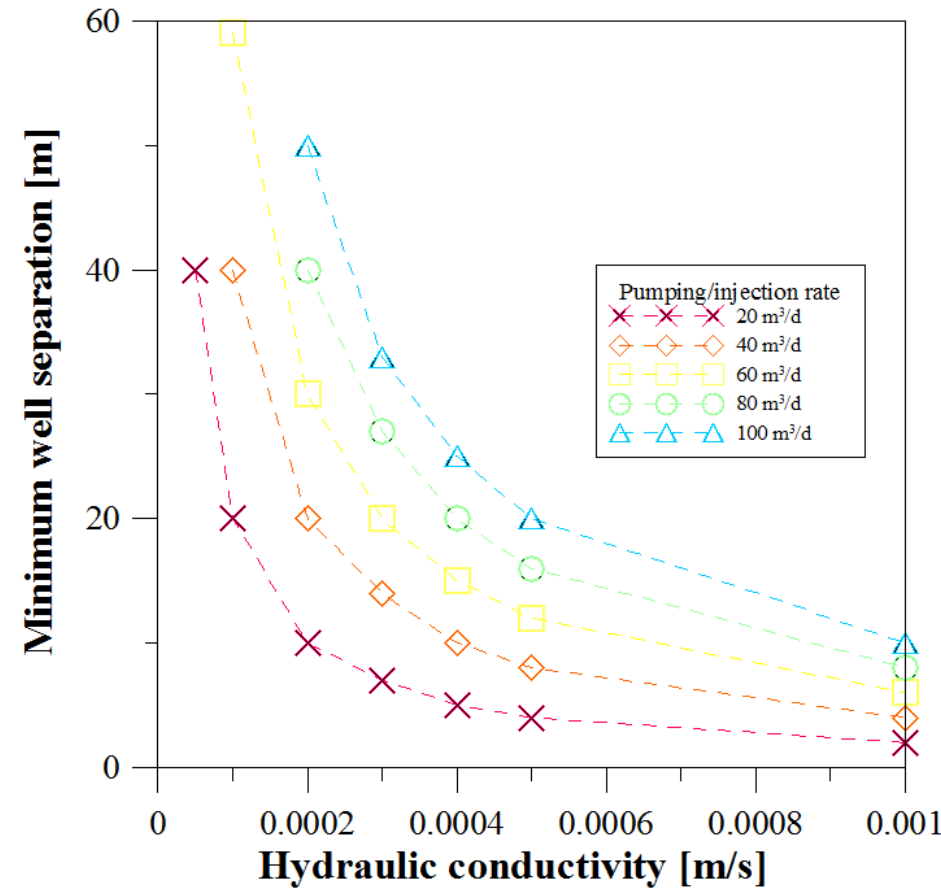

Figure 4 Minimum well separation according to various pumping/injection rates and hydraulic conductivity under medium flow condition (hydraulic gradient $\mathrm{i}=0.005$ ).

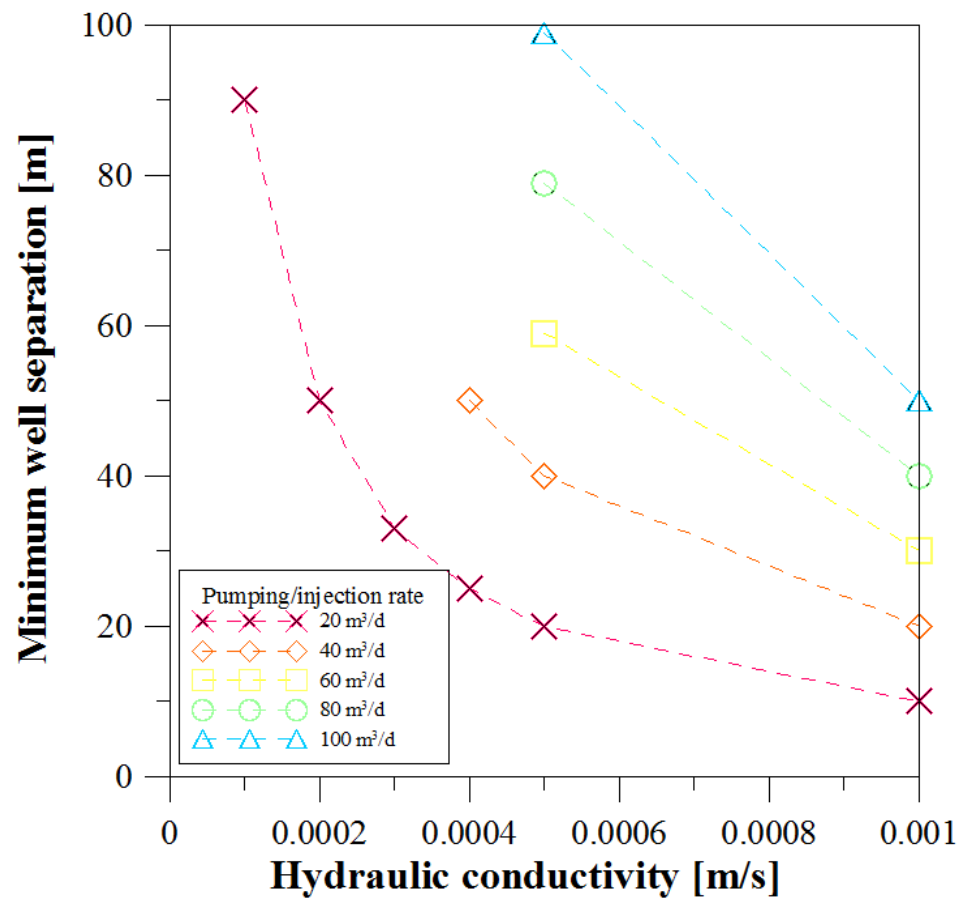

Figure 5 Minimum well separation according to various pumping/injection rates and hydraulic conductivity under low flow condition (hydraulic gradient $\mathrm{i}=0.001$ ). 


\section{CONCLUSION}

The distribution of hydraulic conductivity was estimated from the data obtained from 126 NGWSs over South Korea. Based on the estimated hydraulic properties, the well distance to avoid thermal interferences was calculated with different pumping/injection rates and hydraulic gradients. The results indicated that groundwater flow condition is an important parameter in the design of small GWHP systems, and such applications can be limited by available space especially when groundwater flow is very slow (See Figure 5). Further studies are needed to make the guideline for the design of small GWHP systems.

\section{ACKNOWLEDGMENTS}

This work was supported by the X-project supported by NRF of Korea and the Geowater+ project in "Water Resources Management Program (code 11 Technology Innovation C05)" of the MOLIT and the KAIA of Korea. The BK 21 PLUS project of the Korean government also supported this study.

\section{REFERENCES}

Al-Zyoud, S. and W. Rühaak, and I. Sass. 2014. Dynamic numerical modeling of the usage of groundwater for cooling in north east Jordan - A geothermal case study. Renewable Energy 62: 63-72.

Casasso, A. and R. Sethi. 2015. Modelling thermal recycling occurring in groundwater heat pumps (GWHPs). Renewable Energy 77: 86-93.

Domenico, P. A. and F. W. Schwartz. 1998. Physical and chemical hydrogeology (Vol. 506). New York: Wiley.

KEA (Korea Energy Agency). 2011. New and Renewable Energy RD\&D Strategy 2030 [Geotherm]. Yongin, Korea: KEA.

KEA (Korea Energy Agency). 2015. New and Renewable Energy Statistics 2014. Yongin, Korea: KEA.

Kwon, K.-S., J.-Y. Lee, and J.-K. Mok. 2012. Update of Current Status on Ground Source Heat Pumps in Korea (2008-2011). Journal of the Geological Society of Korea 48(2): 193-199.

Lee, J.-Y. 2009. Current status of ground source heat pumps in Korea. Renewable and Sustainable Energy Reviews 13: 1560-1568.

Lo Russo, S., G. Taddia, G. Baccino, and V. Verda. 2011. Different design scenarios related to an open loop groundwater heat pump in a large building: Impact on subsurface and primary energy consumption. Energy and Buildings 43: 347-357.

Mok, J.-G., H.-G. Lim, B.-J. Jang, Y.-C. Park, and J.-Y. Lee. 2010. Time Series Analysis of the Effect of Ground-source Heat Pumps on Groundwater Characteristics. The Journal of Engineering Geology 21(1): 35-43.

Stauffer, F., P. Bayer, P. Blum, N. Molina-Giraldo, and W. Kinzelbach. 2013. Thermal Use of Shallow Groundwater (Vol. 265). CRC Press.

Zhou, X., Q. Gao, X. Chen, M. Yu, and X. Zhao. 2013. Numerically simulating the thermal behaviors in groundwater wells of groundwater heat pump. Energy 61: 240-247. 